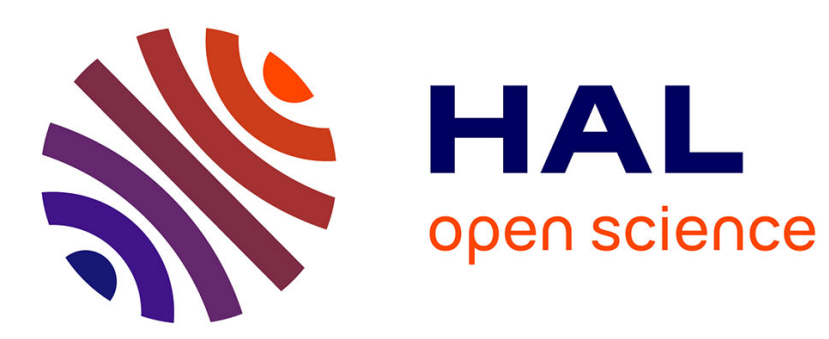

\title{
Sb-surfactant mediated growth of Ge nanostructures
}

\author{
A. Portavoce, A. Ronda, I. Berbezier
}

\section{To cite this version:}

A. Portavoce, A. Ronda, I. Berbezier. Sb-surfactant mediated growth of Ge nanostructures. Materials Science and Engineering, 2002, 89, pp.205 - 210. hal-02393607

\section{HAL Id: hal-02393607 https://hal-amu.archives-ouvertes.fr/hal-02393607}

Submitted on 4 Dec 2019

HAL is a multi-disciplinary open access archive for the deposit and dissemination of scientific research documents, whether they are published or not. The documents may come from teaching and research institutions in France or abroad, or from public or private research centers.
L'archive ouverte pluridisciplinaire HAL, est destinée au dépôt et à la diffusion de documents scientifiques de niveau recherche, publiés ou non, émanant des établissements d'enseignement et de recherche français ou étrangers, des laboratoires publics ou privés. 


\title{
Sb-surfactant mediated growth of Ge nanostructures
}

\author{
A. Portavoce ${ }^{\mathrm{a}, \mathrm{b}}$, A. Ronda ${ }^{\mathrm{a}}, \mathrm{I}$. Berbezier ${ }^{\mathrm{a}, *}$ \\ ${ }^{\text {a } C R M C 2}$ - CNRS Case 913, Campus de Luminy, 13288 Marseille Cedex 9, France \\ ${ }^{\mathrm{b}}$ L2MP Faculté des Sciences de St Jérôme, Case 511, 13397 Marseille, France
}

\begin{abstract}
This paper reports the AFM and HREM study of the $\mathrm{Sb}$ surfactant mediated growth of $\mathrm{Ge}$ on $\mathrm{Si}\left(\begin{array}{lll}0 & 0 & 1\end{array}\right)$. We show that very dense self-organised Ge dots of small lateral dimensions can be grown by using a sub-monolayer coverage of $\operatorname{Sb}$ on $\operatorname{Si}\left(\begin{array}{llll}0 & 0\end{array}\right)$ in the transient growth regime between 2D nucleation and step flow. The dramatic Ge growth change induced by Sb is attributed to both kinetic and thermodynamic effects. Indeed, HREM observations evidence mainly two phenomena: the close-packing of ultra-small Ge islands indicating a lower surface diffusion in presence of $\mathrm{Sb}$ and a mono-modal island shape and size that strongly differs from the bimodal islands 'huts' and 'domes' commonly observed without Sb. Morphological and microstructural features of $\mathrm{Ge}$ islands formed with and without $\mathrm{Sb}$ are studied and the differences between facets and aspect ratio are exhibited. Moreover, at lower growth temperature (in the $2 \mathrm{D}$ nucleation regime, $T_{\mathrm{g}} \leqslant 350{ }^{\circ} \mathrm{C}$ ), a delay to $3 \mathrm{D}$ island nucleation is observed and defect free 2D flat layers can be grown up to thicknesses of $\sim 18 \AA$. At higher growth temperature, (in pure step flow at $T_{\mathrm{g}} \sim 750{ }^{\circ} \mathrm{C}$ ) large, well separated 'dome' islands partially relaxed by dislocation nucleation on their edges are obtained. Such islands are very similar to those obtained without $\mathrm{Sb}$ coverage. The complete desorption of $\mathrm{Sb}$ on $\mathrm{Ge}$ rich surface at $T>720{ }^{\circ} \mathrm{C}$ explains this result. This study which improves the understanding on the formation of ultra-small dense islands is very promising for the fabrication of quantum devices that require highly homogeneous islands of small lateral sizes and of MOSFET heterostructures with strained SiGe n-channel which require flat Ge rich layers with abrupt interfaces. (C) 2002 Elsevier Science B.V. All rights reserved.
\end{abstract}

Keywords: Sb; Surfactant mediated growth; Quantum dots; Ge; Si(0 0 1); Molecular beam epitaxy

\section{Introduction}

$\mathrm{Si}\left(\begin{array}{lll}0 & 0 & 1\end{array}\right)$ surface is expected to remain the most widely used surface for homo- and hetero-epitaxy for microelectronic device applications in the next 20 years with the $\mathrm{SiGe}$ heterostructures being increasing their market place. The latter are already fabricated by most of the largest companies in hetero bipolar transistors (HBT) and present great interest for future microelectronic (MODFET) and nanoelectronic (single electron transistor and nanocrystal memories) devices.

Two ways to realise heterostructures have to be distinguished depending if devices are based on $\mathrm{Si}_{1-X} \mathrm{Ge}_{X}$ films (strained or relaxed) or on Ge quantum dots. In the first case, the aim is to produce flat layers with abrupt interfaces and low defect concentrations (in

\footnotetext{
* Corresponding author. Tel.: + 33-6-6036-2813; fax: + 33-4-91418916.

E-mail address: berbezier@crmc2.univ-mrs.fr (I. Berbezier).
}

bulk and at interfaces). Difficulties to realise this type of structure come first from the stress induced by the lattice parameter mismatch $(4 \%)$ and second from the lower surface energy of $\mathrm{Ge}$ as compared to Si. These two phenomena lead to a Stranski-Krastanov growth mode of $\mathrm{Ge}$ on Si. Schematically, two critical thicknesses which limit $\mathrm{Si}_{1-X} \mathrm{Ge}_{X}$ layers epitaxy on $\mathrm{Si}$ have to be considered. One corresponds to the critical thickness beyond which $3 \mathrm{D}$ islands begin to form. For sake of clarity, all the $\mathrm{Si}_{1-X} \mathrm{Ge}_{X}$ metastable states induced by the interplay of kinetics and of thermodynamics on $\operatorname{Si}\left(\begin{array}{lll}0 & 0 & 1\end{array}\right)$ will not be described here. This thickness is directly related to the elastic strain energy. The other corresponds to the critical thickness beyond which dislocations nucleate. It is related to the balance between stress relaxation and stress gradient induced by the dislocation. Moreover, other difficulties arise from the Ge surface segregation (induced by growth kinetics, stress and surface energy) and the significant $\mathrm{Si} / \mathrm{Ge}$ intermixing, which leads to broad interfaces. But the 

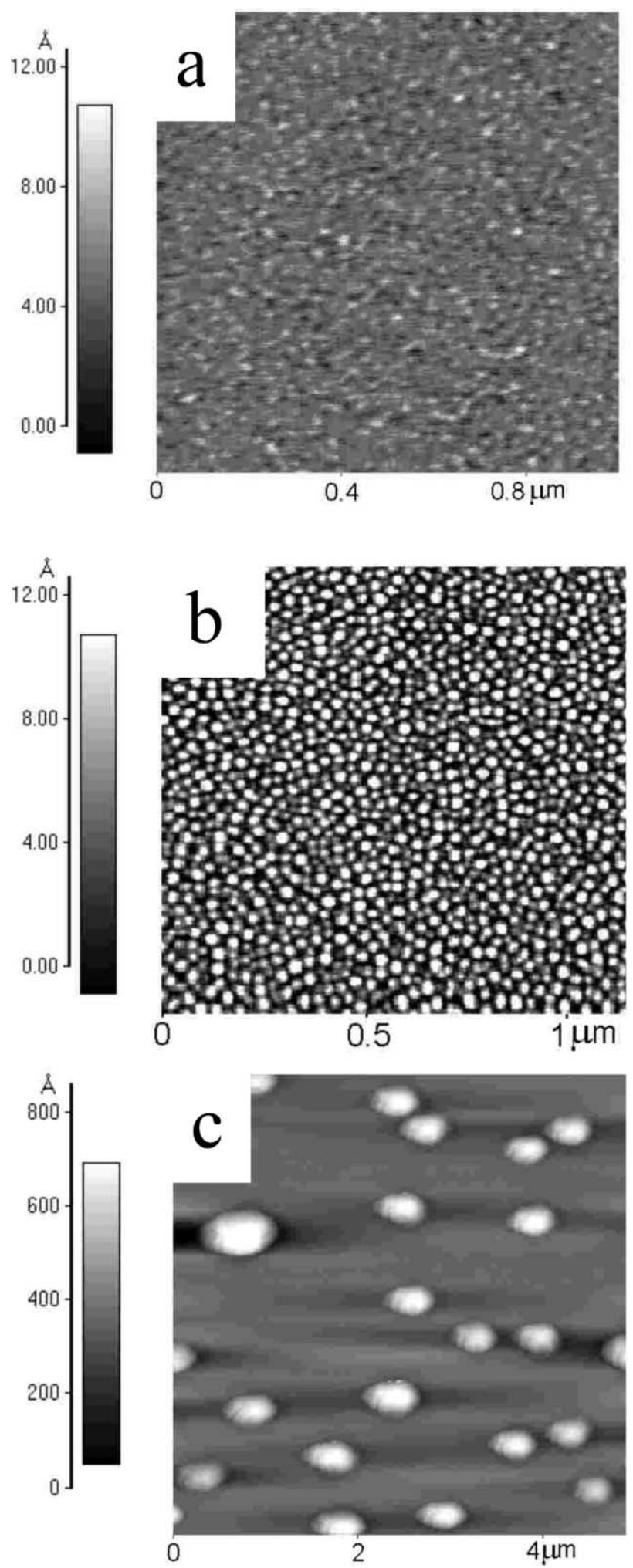

Fig. 1. Surface AFM images after the growth of $18 \AA$ of Ge on $1 \mathrm{ML}$ $\mathrm{Sb} / \mathrm{Si}\left(00\right.$ 1): (a) $T_{\mathrm{g}}=350{ }^{\circ} \mathrm{C}$, (b) $T_{\mathrm{g}}=550{ }^{\circ} \mathrm{C}$ and (c) $T_{\mathrm{g}}=750{ }^{\circ} \mathrm{C}$.

use of a group $\mathrm{V}$ surfactant element can solve several of these problems. Indeed, it was reported $[4,5,9,11$, $12,15,17,22,23]$ that surfactant mediated growth could suppress or at least delay islands formation and permit to grow thicker smooth $\mathrm{Si}_{1-X} \mathrm{Ge}_{X}$ layers with higher $\mathrm{Ge}$ concentration. The use of a surfactant is also reported to decrease the Ge segregation $[1,6,11,15,16]$ and the interface $\mathrm{Si} / \mathrm{Ge}$ intermixing $[4-7,9,11,15,16,20-23]$. In addition, the use of a surfactant seems to be an interesting process to realise $\mathrm{SiGe}$ or Ge relaxed layers grown on $\mathrm{Si}$ substrates $[13,14]$ with lower threading dislocation density and lower surface roughness.

On another side, the realisation of quantum devices based on Ge quantum dots meets different difficulties more related to the mechanisms of nucleation, evolution and self-assembling of islands. Lithographic and complex technological processes will not be envisaged here because of the huge additional cost induced by the fabrication. Indeed, after the growth of 3-4 ML of Ge on $\operatorname{Si}\left(\begin{array}{lll}0 & 0 & 1\end{array}\right), 3 \mathrm{D}$ 'hut' islands with very low aspect ratio (large lateral sizes and low height) begin to form. They rapidly elongate into rectangular flat islands and then transform into large rounded 'domes'. Such first-degree shape transformation is related to both surface kinetics (coarsening process) and energetics (stress relaxation). But the lateral sizes of these islands are much too large to obtain quantum confinement effect. The use of a predeposited impurity is a relevant way to reduce the lateral size of Ge dots [18] and $\mathrm{Sb}$ (element of group V) which is the most commonly n-type dopant used in MBE seems to be a good candidate for that. Indeed, in order to reduce the lateral size of islands, different ways can be explored: the reduction of the ad-atom surface diffusion (and this has been shown for group $\mathrm{V}$ elements $[1,10,11,20])$; the increasing of stress (by decreasing the $\mathrm{Si} / \mathrm{Ge}$ intermixing for instance); the increasing of islands nuclei density [3,24].

However, in spite of encouraging results, the physical mechanism by which a surfactant modifies the $\mathrm{Ge} / \mathrm{Si}$ growth mode remains unsolved, notably about the $\mathrm{Sb}$ effect since contradictory results (both theoretical and experimental) are reported in the literature. Indeed, while some results reveal crystallinity damages induced by $\mathrm{Sb}$ mediated growth $[2,8]$ others show a decrease of the defect density [9]. In addition, $\mathrm{Sb}$ has also been shown to increase the surface and interface roughness $[2,6,8,10,12]$ instead of promoting $\mathrm{Ge}$ epitaxy on $\mathrm{Si}$ $[4,9,12,15,17,23]$.

In order to improve our basic understanding of the $\mathrm{Ge} / \mathrm{Si}\left(\begin{array}{lll}0 & 0 & 1\end{array}\right)$ growth mechanisms in presence of a sub monolayer $\mathrm{Sb}$ coverage, this paper presents an AFM and HREM study of the nanostructures formed. The influence of $\mathrm{Sb}$ coverage, growth temperature $\left(T_{\mathrm{g}}\right)$ and deposited thickness are investigated. Peculiar attention is paid to the transient growth regime between 2D nucleation and step flow. We show that it is possible to grow ultra-small mono-modal dense $\mathrm{Ge}$ islands in this regime. This is explained by the thermodynamics (decrease of the surface energy, increase of strain energy) and kinetics (decrease of the surface diffusion) changes induced by $\mathrm{Sb}$. 


\section{Experimental}

All the structures were grown in a Riber MBE system with a base pressure typically $<10^{-11}$ Torr. Floating zone silicon was evaporated thermally from an electron beam evaporator. Ge and $\mathrm{Sb}$ were evaporated from effusion Knudsen cells. Boron doped $\operatorname{Si}\left(\begin{array}{lll}0 & 0 & 1\end{array}\right)$ wafers of nominal orientation (miscut $<0.2^{\circ}$ ) were ex situ cleaned and protected by an oxide layer as a final step. Subsequent in situ cleaning consisting in thermal desorption of the oxide layer at temperature about $900{ }^{\circ} \mathrm{C}$ was realised. A $50 \mathrm{~nm}$ thick $\mathrm{Si}$ buffer layer was systematically grown to achieve reproducible surface whose cleanness is qualitatively checked by the $(2 \times 1)$ reconstruction streaks intensity. Two types of Ge nanostructures were realised either deposited on $\mathrm{Sb}$ sub-monolayer or directly deposited on $\operatorname{Si}\left(\begin{array}{lll}0 & 0 & 1\end{array}\right)$. The effect of temperature (and consequently also growth mode), deposited thickness and $\mathrm{Sb}$ coverage on the shape and stress relaxation of Ge nanostructures were studied. Morphology and microstructure of samples were observed by AFM and HREM (JEOL 4000 EX), respectively.

\section{Results}

Fig. 1 shows the evolution of the Ge surface morphology (thickness $\sim 18 \AA$ ) with the growth temperature. First, the different growth mode at 350 and $550{ }^{\circ} \mathrm{C}$ or $750{ }^{\circ} \mathrm{C}$ are clearly seen. At $350{ }^{\circ} \mathrm{C}$ (Fig. 1a and Fig. 2) the surface is flat with a root mean square surface roughness about $5 \AA$ suggesting the onset of 3D island nucleation $(L \sim 20-30 \mathrm{~nm})$. It is only at $550{ }^{\circ} \mathrm{C}$ that small dense Ge islands can be formed. At higher temperature, large isolated islands (Fig. 4b) grow over flat surfaces. Such islands are very similar to those obtained for pure Ge growth (large dislocated domes). This result confirms the desorption of $\mathrm{Sb}$ at this temperature and indicates that $\mathrm{Sb}$ partial desorption during Ge growth at lower temperatures should also be considered as a possible way to modify growth (increase of the density of nucleation centres). Since it was shown that $\mathrm{Sb}$ desorbs from $\mathrm{SiGe}$ surface even at $550{ }^{\circ} \mathrm{C}$ but not at $350{ }^{\circ} \mathrm{C}$ [24], it is a relevant difference between growth at $550{ }^{\circ} \mathrm{C}$ and at $350{ }^{\circ} \mathrm{C}$ to take into account.

For comparison, Fig. 3 shows the surface morphology of $\mathrm{Ge} / \mathrm{Si}$ without $\mathrm{Sb}$ at $T_{\mathrm{g}}=550{ }^{\circ} \mathrm{C}$. The commonly observed bimodal 'huts' (Fig. 4a) and 'domes' (Fig. 4c) islands are visible. Lateral sizes, height and densities of islands formed with and without $\mathrm{Sb}$ coverage are summarised in Table 1 . The increase of islands density $(\times 3.75)$ and decrease of lateral islands size (/2.5) induced by $\mathrm{Sb}$ is clearly evidenced.

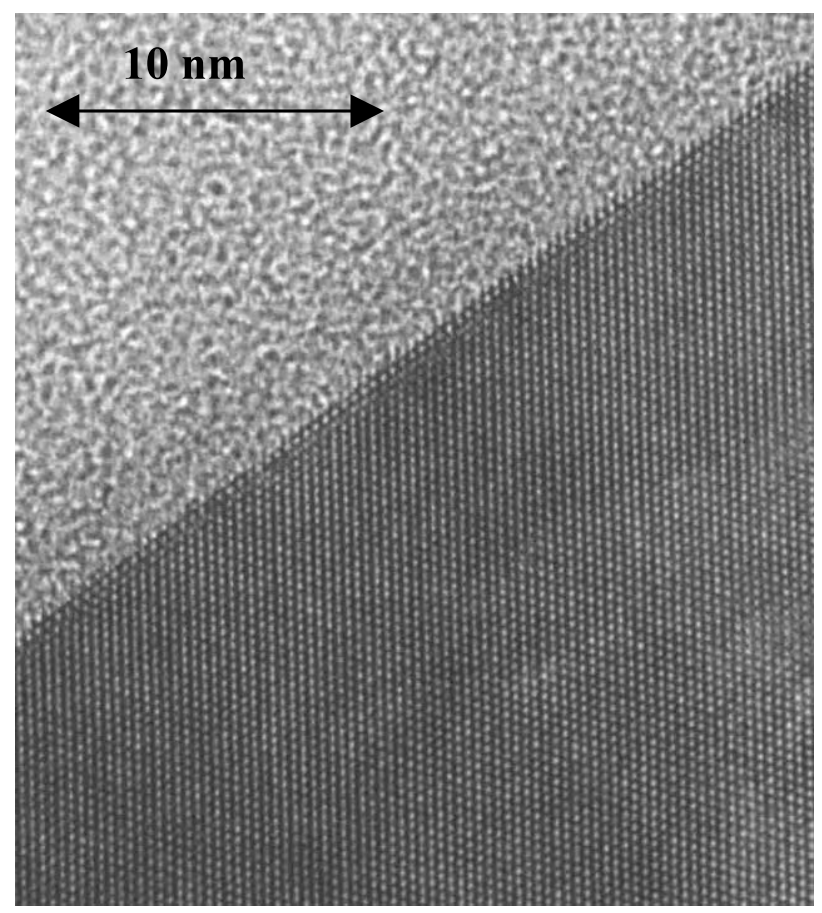

Fig. 2. Cross-section TEM image of the $1 \mathrm{ML} \mathrm{Sb}$ mediated growth of $18 \AA$ of Ge with $T_{\mathrm{g}}=350{ }^{\circ} \mathrm{C}$.

HREM observations of $\mathrm{Ge} / \mathrm{Si}$ (Fig. 4) samples confirm the presence of the expected [ $\left[\begin{array}{lll}1 & 0 & 5\end{array}\right]$ facets in huts islands (at $11.3^{\circ}$ of $\left(\begin{array}{lll}0 & 0 & 1\end{array}\right)$ plane) $[10,11]$. Concerning domes two different facets can easily be observed with angles about $25^{\circ} \pm 1$ and $55^{\circ} \pm 1$. They correspond to $\left\{\begin{array}{lll}1 & 1 & 3\end{array}\right\}$ and $\left\{\begin{array}{lll}1 & 1 & 1\end{array}\right\}$ (at $25.2^{\circ}$ and $54.7^{\circ}$ of $\left(\begin{array}{lll}0 & 0 & 1\end{array}\right)$ surface, respectively) that are low energy planes commonly observed in equilibrium shape of $\mathrm{Si}$. Even if some smaller facets can also be distinguished their angles cannot be accurately determined (an angle about $13^{\circ}$ was also measured for the 'meniscus' at the base of the island which could correspond to (1 116$)$ facets), neither the orientation of the top of the island which presents a rounded shape.

Fig. 1b shows the morphology of the surface for the growth of Ge in same conditions but with the predeposition of $1 \mathrm{ML}$ of $\mathrm{Sb}$. In this case, only one type of small islands is obtained (Fig. 5). Due to the small extension of facets (small lateral size of islands), it is not possible to determine their exact orientations. However, these islands do not have a shape similar to huts neither to domes. TEM images also evidence the small distance separating islands bases. The formation of smaller dots with a higher density can be interpreted as a diminution of the surface diffusion (in these conditions of growth, islands do not touch each other). Moreover, high-resolution images show that such islands are dislocation free and consequently fully strained, which is the case for huts but not for most of 
the domes islands. This is in good agreement with our previous results [25]: the existence of two types of Ge islands (hut and domes) is related to the stress relaxation, hut allows relaxation about $0.25 \%$ and domes about $0.85 \%$. However, in presence of $\mathrm{Sb}$, which is known to reduce the surface energy of both $\mathrm{Si}$ and $\mathrm{Ge}$ $[4,19]$, island shape changes induced by surface energy changes [10] could be expected.

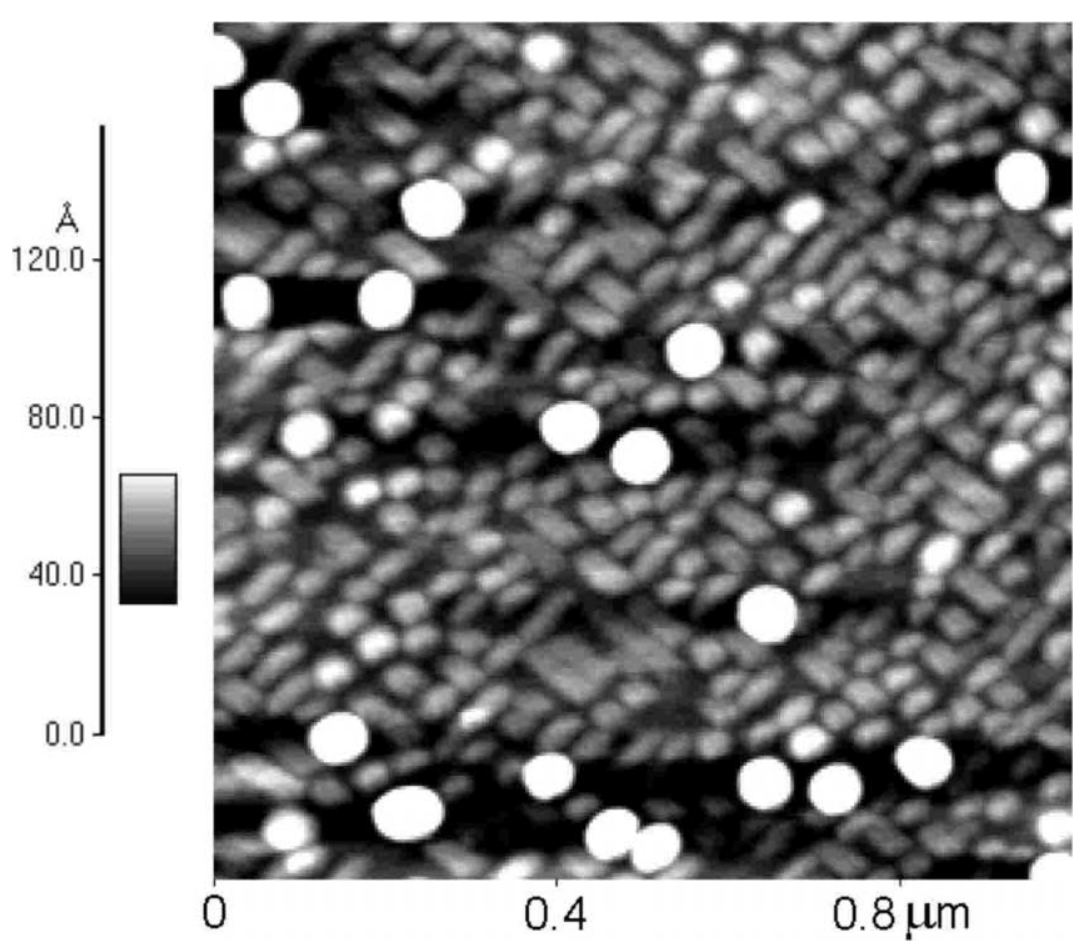

Fig. 3. Surface AFM image after the growth of $18 \AA$ of $\mathrm{Ge}$ on $\operatorname{Si}\left(\begin{array}{lll}0 & 0 & 1\end{array}\right)$.
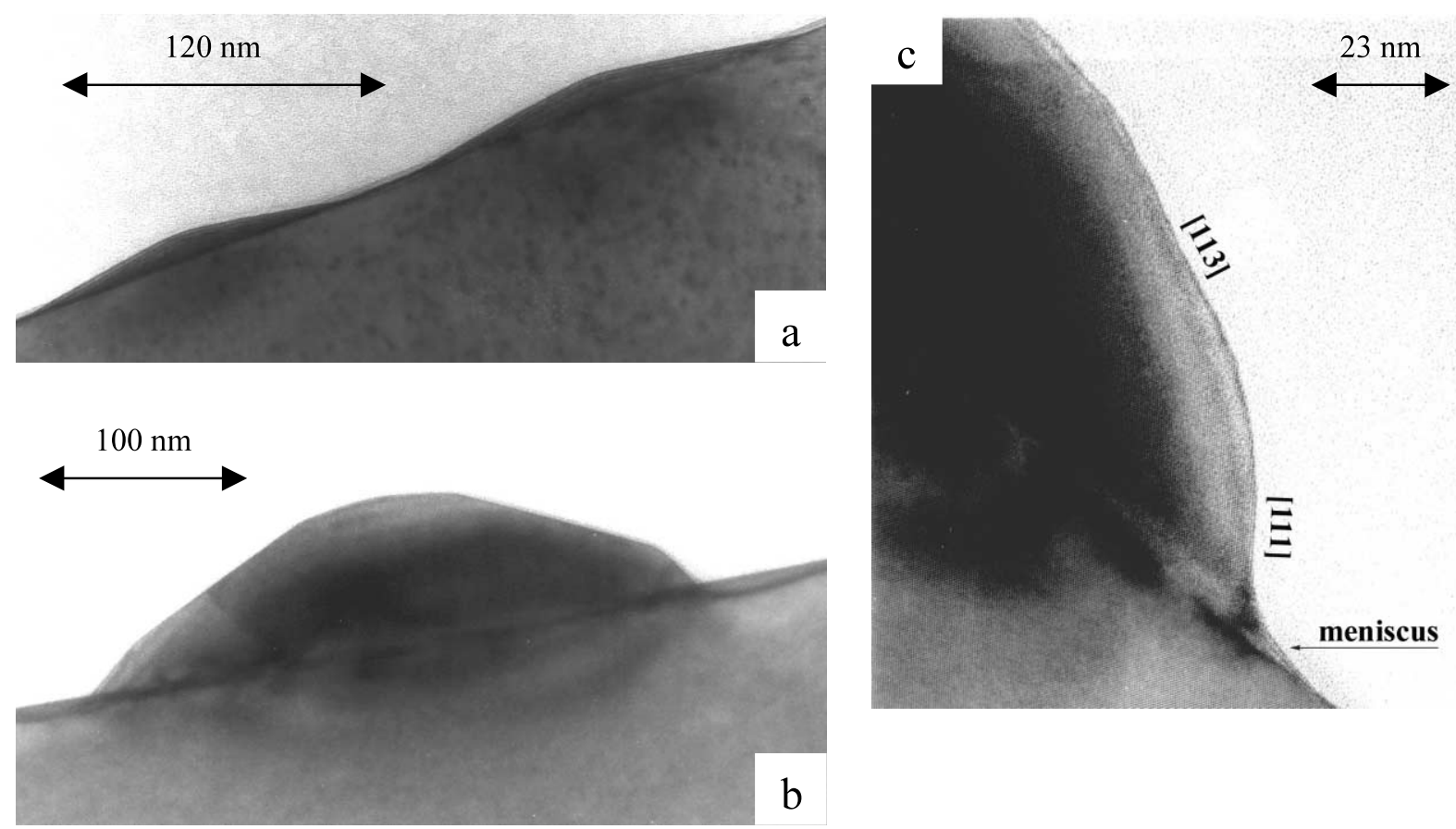

Fig. 4. Cross-section TEM images of islands formed after the growth of $18 \AA$ of Ge on $\operatorname{Si}\left(\begin{array}{lll}0 & 0 & 1\end{array}\right)$ : (a) hut $T_{\mathrm{g}}=550{ }^{\circ} \mathrm{C}$, (b) dome $T_{\mathrm{g}}=750{ }^{\circ} \mathrm{C}$ and (c) dome $T_{\mathrm{g}}=550{ }^{\circ} \mathrm{C}$. 

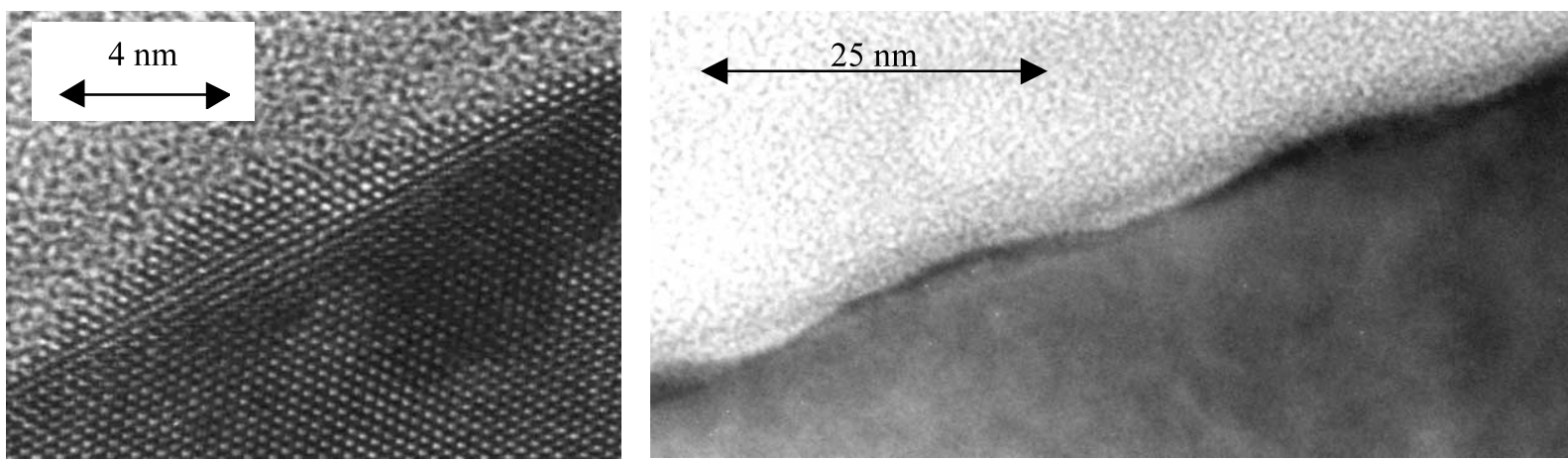

Fig. 5. Cross-section TEM images of ultra-small islands formed after the growth of $18 \AA$ of $\mathrm{Ge}$ on $1 \mathrm{ML} \mathrm{Sb} / \mathrm{Si}(001)$ at $T_{\mathrm{g}}=550{ }^{\circ} \mathrm{C}$.

Table 1

Islands lateral size, height and surface density versus Ge thickness and predeposited $\mathrm{Sb}$ coverage

\begin{tabular}{lllll}
\hline Ge thickness $(\AA)$ & 9 & 12 & 18 & 27 \\
$\begin{array}{l}\text { Later size }(\AA) \\
\text { Without Sb }\end{array}$ & 350 & & $400 \times 700,800^{\mathrm{a}}$ & \\
With $1 \mathrm{ML} \mathrm{Sb}$ & 250 & 300 & $\begin{array}{l}300 \\
460\end{array}$ & 660 \\
With $1 / 2 \mathrm{ML} \mathrm{Sb}$ & & & & \\
Height $(\AA)$ & & & $20,100^{\mathrm{a}}$ & \\
Without Sb & 20 & & 10 & 30 \\
With $1 \mathrm{ML} \mathrm{Sb}$ & $<10$ & 8 & 20 & \\
With $1 / 2 \mathrm{ML} \mathrm{Sb}$ & & & & \\
$\begin{array}{l}\text { Density }\left(\text { dots } / \mathrm{cm}^{2}\right) \\
\text { Without Sb }\end{array}$ & & & $4 \times 10^{10}, 2 \times 10^{9 \mathrm{a}}$ & \\
With $1 \mathrm{ML} \mathrm{Sb}$ & $10^{8}$ & $6 \times 10^{10}$ & $1.5 \times 10^{11}$ & $2 \times 10^{10}$ \\
With $1 / 2 \mathrm{ML} \mathrm{Sb}$ & & & $5 \times 10^{10}$ & \\
\end{tabular}

${ }^{\text {a }}$ Hut, dome.

Table 1 summarises the evolution of the lateral size, height and density of islands as a function of $\mathrm{Ge}$ thickness and $\mathrm{Sb}$ coverage at $T_{\mathrm{g}}=550{ }^{\circ} \mathrm{C}$. For the $\mathrm{Sb}$ mediated growth, when the Ge thickness increases, dots sizes do not vary a lot to a thickness of $18 \AA$ but islands surface density increases. It means that the surface diffusion is constant during the growth and for a thickness of $27 \AA$ the maximal islands surface density is raised and bigger dots with lower density are obtained. For the growth of $9 \AA$ of $\mathrm{Ge}$, the island density is $10^{9} / \mathrm{cm}^{2}$ without $\mathrm{Sb}$ and $10^{8} / \mathrm{cm}^{2}$ with $\mathrm{Sb}$. This result indicates that $\mathrm{Sb}$ delays the island nucleation and promotes the Ge epitaxy even at $T_{\mathrm{g}}=550{ }^{\circ} \mathrm{C}$. But Fig. $1 \mathrm{~b}$ and Fig. 3 point out that in spite of delay the dots nucleation $\mathrm{Sb}$ increases the number of nucleation sites. Moreover, dots sizes decrease when $\mathrm{Sb}$ coverage increases showing the direct relation between the surface diffusion and the $\mathrm{Sb}$ coverage. As $\mathrm{Sb}$ allows to delay the island nucleation and decreases the $\mathrm{Si} / \mathrm{Ge}$ intermixing, the strain in the Ge layer is important and when a thickness limit is raised islands appears. Due to the low surface diffusion induced by $\mathrm{Sb}$ atoms on the surface and to the important strain stored up, islands sizes are reduced as compared to islands obtained without $\mathrm{Sb}$.

\section{Conclusion}

AFM and HREM study of the Sb surfactant effect on the $\mathrm{Ge} / \mathrm{Si}\left(\begin{array}{lll}0 & 0 & 1\end{array}\right)$ growth was performed. First $\mathrm{Sb}$ effect was found to depend on the temperature: flat surface was obtained at low temperature $\left(350{ }^{\circ} \mathrm{C}\right)$ and small island $(\varnothing \approx 30 \mathrm{~nm})$ with high surface density $\left(1.5 \times 10^{11} / \mathrm{cm}^{2}\right)$ and homogeneous surface distribution at higher temperature $\left(550^{\circ} \mathrm{C}\right)$. Sb was found to delay the island nucleation (even at $550{ }^{\circ} \mathrm{C}$ ), to decrease the ad-atoms surface diffusion, to change the equilibrium shape of islands, and to increase the number of island nucleation sites. Then playing a role on the kinetic of growth, on thermodynamic parameters and on the stored up strain of the film, Sb mediated growth was found to be an interesting tool to realise both very small Ge islands and Ge smooth surfaces.

\section{References}

[1] C.W. Oh, E. Kim, Y.H. Lee, Phys. Rev. Lett. 76 (1996) 776.

[2] X. Lu, Z. Jiang, D. Huang, H. Zhu, X. Zhang, X. Wang, J. Cryst. Growth 158 (1996) 169.

[3] C.S. Peng, Q. Thuang, W.Q. Cheng, J.M. Zhou, Y.H. Zhang, T.T. Sheng, C.H Tung, Appl. Phys. Lett. 72 (1998) 2541.

[4] S.J. Jenkins, G.P. Srivastava, Phys. Rev. B 56 (1997) 9221.

[5] G. Brill, D.J. Smith, D. Chandrasekhar, Y. Gogotsi, A. Prociuk, S. Sivananthan, J. Cryst. Growth 202 (1999) 538.

[6] G.G. Jernigan, C.L. Silvestre, M. Fatemi, M.E. Twigg, P.E. Thompson, J. Cryst. Growth 213 (2000) 299.

[7] Z.M. Jiang, C.W. Pei, X.F. Zhou, W.R. Jiang, B. Shi, X.H. Liu, X. Wang, Q.J. Jia, W.L. Zheng, X.M. Jiang, Appl. Phys. Lett. 75 (1999) 370.

[8] K.S. Kim, Y. Takakuwa, T. Abukawa, S. Kono, J. Cryst. Growth 186 (1998) 95.

[9] M. Katayama, T. Nakayama, M. Aono, C.F. McConville, Phys. Rev. B 54 (1996) 8600.

[10] M. Horn-von Hoegen, B.H. Müller, A. Al-Falou, M. Henzler, Phys. Rev. Lett. 71 (1993) 3170.

[11] W. Rodrigues, O. Sakata, T.L. Lee, D.A. Walko, D.L. Marasco, M.J. Bedzyk, J. Appl. Phys. 88 (2000) 2391.

[12] J.R. Power, K. Hinrichs, S. Peters, K. Haberland, N. Esser, W. Richter, Phys. Rev. B 62 (2000) 7378.

[13] D. Reinking, M. Kammler, M. Horn VonHoegen, K.R. Hofmann, Appl. Phys. Lett. 71 (1997) 924. 
[14] J.L. Liu, C.D. Moore, G.D. U'Ren, Y.H. Luo, Y. Lu, G. Jin, S.G. Thomas, M.S. Goorsky, K.L. Wang, Appl. Phys. Lett. 75 (1999) 1586.

[15] S. Kanakaraju, A.K. Sood, S. Mohan, Phys. Rev. B 61 (2000) 8334.

[16] R. Gunnella, P. Castrucci, N. Pinto, P. Cucculelli, I. Davoli, D. Sebilleau, M. De Crescenzi, Surf. Rev. Lett. 5 (1998) 157.

[17] S.J. Jankins, G.P. Srivastava, Surf. $\quad$ Sci. 398 (1998) L308.

[18] H. Takamiya, M. Miura, N. Usami, T. Hattori, Y. Shiraki, Thin Solid Films 369 (2000) 84.

[19] S.C.A. Gay, G.P. Srivastava, Surf. Sci. 443 (1999) 253.
[20] K. Sakamoto, K. Miki, T. Sakamoto, H. Matsuhata, K. Kyoya, J. Cryst. Growth 127 (1993) 392.

[21] Z.M. Jiang, A. Xu, D.Z. Hu, H.J. Zhu, X.H. Liu, X.J. Wang, M.C. Mao, X.J. Zhang, J.H. Hu, D.M. Huang, X. Wang, Thin Solid Films 321 (1998) 116.

[22] M.E. Gonzales-Mendez, N. Takeuchi, Revista Mexicana de Fisica 46 (2000) 84.

[23] P. Castrucci, R. Gunnella, N. Pinto, R. Bernardini, M. De Crescenzi, M. Sacchi, Surf. Rev. Lett. 7 (2000) 307.

[24] A. Portavoce, F. Volpi, A. Ronda, P. Gas, I. Berbezier, Thin Solid Films 380 (2000) 164.

[25] F. Volpi, A. Portavoce, A. Ronda, Y. Shi, J.M. Gay, I. Berbezier, Thin Solid Films 380 (2000) 46. 